\title{
Antibody-Capture Enzyme-Linked Immunosorbent Assay for Detection of Antibody to Turkey Coronavirus Using Infectious Bronchitis Virus or Recombinant Nucleocapsid Protein as Coating Antigen
}

\author{
Chien Chang Loa, Mohamed Abdelwahab, Yi-Ning Chen, \\ Ming-Kun Hsieh, Ching Ching Wu, and Tsang Long Lin
}

\begin{abstract}
Turkey coronavirus (TCoV) infection continues to threaten turkey industry. Because specific treatment and effective vaccination program are not available, rapid and cost-effective detection of antibodies to $\mathrm{TCoV}$ infection is an important control measure to monitor the disease status in the fields. Two antibodycapture enzyme-linked immunosorbent assay (ELISA) procedures for detection of antibodies to TCoV are outlined in this chapter. One ELISA method uses chicken infectious bronchitis coronavirus (IBV) as the coating antigen based on antigenic cross-reactivity between TCOV and IBV. The other method relies on a recombinant $\mathrm{TCoV}$ nucleocapsid protein. Both methods are useful for serological diagnosis of $\mathrm{TCoV}$ infection in the turkey flocks.
\end{abstract}

Key words Turkey coronavirus, Antibody detection, ELISA, Nucleocapsid, Recombinant protein

1 Introduction

Turkey coronavirus (TCoV) causes an acute and highly contagious enteric disease affecting turkeys of all ages $[1,2]$. TCoV is an important pathogen and remains as a serious threat to the turkey industry. There is currently no specific treatment or effective vaccine for $\mathrm{TCoV}$ infection. In order to rapidly diagnose and effectively control turkey coronaviral enteritis, serological diagnosis of antibodies to $\mathrm{TCOV}$ becomes a critical tool to determine the infectivity of turkeys in the turkey flocks.

Immunofluorescent antibody assay (IFA) for detection of anti$\mathrm{TCoV}$ antibodies has been extensively used for disease outbreaks in the fields. However, IFA procedures are time consuming and labor intensive for handling large numbers of samples. In addition, IFA requires highly trained personnel to prepare frozen sections of

Leyi Wang (ed.), Animal Coronaviruses, Springer Protocols Handbooks,

DOI 10.1007/978-1-4939-3414-0_5, @ Springer Science+Business Media New York 2016 
turkey or turkey embryo intestines and perform fluorescent microscopy.

ELISA method has high specificity and sensitivity and can be applied to large numbers of samples simultaneously. Two ELISA procedures are highlighted in this chapter. One ELISA method utilizing infectious bronchitis virus (IBV) as a coating antigen for detection of antibody to $\mathrm{TCoV}$ is based on antigenic cross-reactivity between TCoV and IBV [3]. The other antibody-capture ELISA uses a recombinant $\mathrm{TCoV}$ nucleocapsid $(\mathrm{N})$ protein as a coating antigen $[4,5]$.

Nucleocapsid protein appears to be the most abundant viral polypeptide in coronavirus infected cells during all stages of infection. Nucleocapsid protein is detected from 3 to $5 \mathrm{~h}$ after infection, at the same time or earlier than the other structural proteins. The only known posttranslational modification of coronavirus $\mathrm{N}$ proteins is phosphorylation [6]. The coronavirus $\mathrm{N}$ protein is immunodominant [7]. Subcloning of the $\mathrm{TCoV} \mathrm{N}$ gene to a prokaryotic expression system has resulted in a high-level induction of recombinant protein in our laboratory [4]. The recombinant TCoV $\mathrm{N}$ protein expressed from the prokaryotic system is expected to maintain its antigenic integrity because it is not glycosylated.

\section{Materials}

\subsection{ELISA with IBV as Coating Antigen}

1. IBV antibody diagnostic kits from IDEXX (Westbrook, Maine, USA).

2. Positive control (PC) serum is the hyperimmune serum against $\mathrm{TCoV}(\mathrm{TCoV} / \mathrm{IN} / 540 / 94)$ prepared from experimentally infected turkeys.

3. Negative control (NC) serum is collected from 4-month-old normal healthy turkeys grown in the isolation room.

4. Goat anti-turkey $\operatorname{IgG}(\mathrm{H}+\mathrm{L})$ conjugated with horseradish peroxidase (HRP) (Kirkegaard \& Perry Laboratories, Gaithersburg, MD, USA).

5. Blocking buffer: PBS $(\mathrm{pH} 7.4)+1 \%$ bovine serum albumin.

6. Wash buffer: PBS (pH 7.4)+0.05\% Tween 20 .

7. Assay buffer: PBS (pH 7.4)+0.05\% Tween $20+1 \%$ bovine serum albumin.

8. Substrate tetramethyl benzidine (TMB) (Sigma-Aldrich Co., St. Louis, MO, USA).

9. Stop solution $2 \mathrm{~N} \mathrm{HCl}$ acid. (Sigma-Aldrich Co.).

10. Plate reader $\left(\operatorname{Vmax}^{\mathrm{TM}}\right.$ model, Molecular Devices Corp., Sunnyvale, CA, USA). 
2.2 ELISA with Recombinant TCoV N Protein as Coating $\mathbf{A g}$
1. Recombinant TCoV N protein (refer to Chapter 4).

2. ELISA plate (Nunc MaxiSorp ${ }^{\circledR}$ flat-bottom 96-well plate, eBioscience, Inc., San Diego, CA, USA).

3. Positive control (PC) serum is the hyperimmune serum against $\mathrm{TCoV}(\mathrm{TCoV} / \mathrm{IN} / 540 / 94)$ prepared from experimentally infected turkeys.

4. Negative control (NC) serum is collected from 4-month-old normal healthy turkeys grown in the isolation room.

5. Coating buffer: PBS buffer, $\mathrm{pH} 7.4$.

6. Blocking buffer: PBS $(\mathrm{pH} 7.4)+1 \%$ bovine serum albumin.

7. Wash buffer: PBS (pH 7.4)+0.05\% Tween-20.

8. Assay buffer: PBS (pH 7.4) $+0.05 \%$ Tween $-20+1 \%$ bovine serum albumin.

9. Goat anti-turkey $\operatorname{IgG}(\mathrm{H}+\mathrm{L})$ conjugated with HRP (Kirkegaard \& Perry Laboratories).

10. Substrate TMB (Sigma-Aldrich Co.).

11. Stop solution $2 \mathrm{~N} \mathrm{HCl}$ acid (Sigma-Aldrich Co.).

12. Plate reader $\left(\operatorname{Vmax}^{\mathrm{TM}}\right.$ model, Molecular Devices Corp.).

\section{Methods (See Notes 1 and 2)}

\subsection{ELISA with IBV as Coating Antigen}

1. Coating: using commercially available IBV coated plate ( see Note 3).

2. (Optional) Blocking: add $150 \mu$ l of Blocking buffer (see Note 4) to each well. Incubation at $37^{\circ} \mathrm{C}$ for $1 \mathrm{~h}$.

3. Samples: wash the plate with Wash buffer for three times. (see Note 7) Samples including PC and NC are prepared at a minimum required dilution of $1: 40$ in Assay buffer. The diluted serum samples are added at $100 \mu \mathrm{l}$ to each corresponding well. Incubation at $37^{\circ} \mathrm{C}$ for $1 \mathrm{~h}$ ( see Note 6).

4. Conjugate: wash the plate with Wash buffer for five times. Goat anti-turkey $\operatorname{IgG}(\mathrm{H}+\mathrm{L})$ conjugated with horseradish peroxidase is diluted at 1:1600 in Assay buffer ( $s e e$ Note 7) and $100 \mu \mathrm{l}$ is added to each well. Incubation at $37^{\circ} \mathrm{C}$ for $\mathrm{l} \mathrm{h}$.

5. Substrate: wash the plate with Wash buffer for five times. Add substrate $\mathrm{TMB}$ at $100 \mu \mathrm{l} / \mathrm{each}$ well. Incubation in the dark at ambient room temperature for $30 \mathrm{~min}$ ( see Note 8 ).

6. Stop: add $100 \mu \mathrm{l} 2 \mathrm{~N} \mathrm{HCl}$ to each well.

7. Reading: The absorbance of each well at $450 \mathrm{~nm}$ is captured by ELISA plate reader. The ELISA value or S/P ratio of each test serum is calculated as (absorbance value of sample serum minus 


\subsection{ELISA \\ with Recombinant TCoV N Protein as Coating Antigen}

absorbance value of negative control serum) divided by (absorbance value of positive control serum minus absorbance value of negative control serum) (see Note 9).

1. Coating: Coat the ELISA plates with recombinant TCoV N protein at $20 \mu \mathrm{g} / \mathrm{ml}$ in coating buffer for $100 \mu \mathrm{l} /$ well (see Note 10) and incubate at a refrigerator $2-8{ }^{\circ} \mathrm{C}$ for $12-16 \mathrm{~h}$ (see Note 11$)$.

2. Blocking: wash the plate with Wash buffer for three times and add $150 \mu$ l of Blocking buffer to each well. Incubation at $37^{\circ} \mathrm{C}$ for $1 \mathrm{~h}$.

3. Samples: wash the plate with Wash buffer for three times. (see Note 5) Samples including PC and NC are prepared at a minimum required dilution of 1:800 (see Note 7) in Assay buffer. The diluted serum samples are added at $100 \mu \mathrm{l}$ to each corresponding well. Incubation at $37^{\circ} \mathrm{C}$ for $\mathrm{l}$ h (see Note 6).

4. Conjugate: wash the plate with Wash buffer for five times. Goat anti-turkey $\operatorname{IgG}(\mathrm{H}+\mathrm{L})$ conjugated with horseradish peroxidase is diluted at 1:10,000 in Assay buffer ( see Note 7) and $100 \mu \mathrm{l}$ is added to each well. Incubation at $37^{\circ} \mathrm{C}$ for $\mathrm{l} \mathrm{h}$.

5. Substrate: wash the plate with Wash buffer for five times. Add TMB substrate at $100 \mu \mathrm{l} / \mathrm{each}$ well. Incubation in the dark at ambient room temperature for $30 \mathrm{~min}$ ( see Note 8).

6. Stop: add $100 \mu \mathrm{l} 2 \mathrm{~N} \mathrm{HCl}$ to each well.

7. Reading: The absorbance of each well at $450 \mathrm{~nm}$ is captured by ELISA plate reader. The ELISA value or S/P ratio of each test serum is calculated as (absorbance value of sample serum minus absorbance value of negative control serum) divided by (absorbance value of positive control serum minus absorbance value of negative control serum) ( see Notes 9, 12, and 13).

\section{Notes}

1. Although incubation temperature at $37{ }^{\circ} \mathrm{C}$ is described for steps of blocking buffer, samples, and conjugate, incubation at room temperature can be a viable alternative when incubator with temperature control is not conveniently located. Please note that the overall assay reactivity (OD readings) will fluctuate along with daily changes of room temperature. However, the end results of ELISA value (S/P ratio) as normalized by an appropriate positive control analyzed on the same plate will not be affected. It is better to keep a record of room temperature for possible trouble shooting when necessary.

2. In between and in the end of each wash cycle, it is important to tap-dry the plates on a stack of paper towel for lower nonspecific background reactivity. 
3. The commercially available ELISA plate coated with a pool of IBV strains including Massachusetts, JMK, Arkansas, Connecticut, Clone 30, D274, and D1466.

4. This blocking step is optional because the commercial dry plate is already blocked through the production process of commercial ELISA kits. The additional blocking step may help rehydrate the coating antigens in the wells before sample incubation step and subsequently enhance assay performance.

5. This wash step may be skipped if preferred. It is okay to add diluted samples after removal of the blocking buffer and tap dry the plate on a stack of paper towels. The presence of blocking buffer residue has limited effect on the next step for sample incubation. The components of blocking buffer including PBS buffer and BSA are also parts of the assay buffer in sample dilutions. This wash step is usually performed in our laboratory to achieve the best possible assay performance.

6. Each sample is analyzed in two wells and the mean ELISA value is reported. When percentage coefficient of variance $(\% \mathrm{CV})$ is $>20 \%$ and both ELISA values are above cutpoint, the result is not reportable and the sample should be reanalyzed. When one or both of the two values is below cutpoint, the sample is considered negative. Each control samples (HPC, LPC, and NC) are analyzed in duplicate $(N=2 ; 4$ wells for two reportable values).

7. Pipetting volume below $10 \mu \mathrm{l}$ may cause inter-assay variation. Any pipetting volume below $5 \mu \mathrm{l}$ is not recommended. To reduce interday variation of dilutions, two steps of dilution may be considered when necessary such as 1:16 and then $1: 100$ for a final dilution at $1: 1600 ; 1: 20$ and then $1: 40$ for a final dilution at $1: 800 ; 1: 100$ and then $1: 100$ for a final dilution at $1: 10,000$.

8. Color development is a result of HRP enzyme reaction. Laboratory environment such as room temperature may have effect on the reaction rate. It is recommended to check the color development throughout the incubation of $30 \mathrm{~min}$ and stop the reaction with acid to prevent overdevelopment or underdevelopment. This may not be easy for the first few runs but not that hard after some experience. It is important to keep the plate from light because the substrate is light sensitive. Wash step may be increased a few more times before the addition of TMB substrate if high background of nonspecific reactivity is observed.

9. Cutoff point determination and system suitability controls: Cutoff point should reflect biological variations among noninfected turkeys in the field in order to differentiate the infected samples with positive results. With IFA remains as the gold 
standard for detection of TCoV antibody in the field, it is an appropriate approach to set up cutoff point based on IFA positive and negative populations. Some acceptable approaches are discussed below for considerations.

Logistic regression analysis: ELISA value of serum samples from the field turkey flocks as positive or negative for TCoV by IFA are compared. The cutoff point is calculated from the logistic equation $\ln [P /(1-P)]=\beta 1 X+\beta 0$, where $X$ is the ELISA value. At the optimum cutoff point of the ELISA value, the probability of the sample being negative $(P)$ would be the same as the probability of the sample being positive $(1-P)$, i.e., $P=1-P=0.5$ or $50 \%$. The cutoff point is determined by solving $0=\beta 1 X+\beta 0$ for $X(\ln [0.5 /$ $(1-0.5)]=\ln (1)=0)$. Logistic regression is used to estimate the coefficients $\beta 1$ and $\beta 0$. Statistical computations are performed using SAS program. The sample numbers $(N)$ of IFA positive and negative population should be at least 30 .

IFA negative population: ELISA values of serum samples $(N \geq 30)$ from the field turkey flocks as negative for TCoV by IFA are populated. Outliers are removed by statistical methods such as Box-plot. Mean and standard deviation (SD) of ELISA values are calculated from the remaining samples. Cutoff point can be calculated for $95 \%$ confidence interval as mean plus $1.645 \mathrm{SD}$ $($ mean $+1.645 \times \mathrm{SD})$ for an estimated $5 \%$ false positive rate.

Normal turkey sera: reactivity of normal turkey sera is consistently at low background signals in both ELISA methods, suggesting analytical variations. Cutoff point based on normal turkey sera does not reflect biological variations and therefore is not functional. ELISA value normalization or cutoff point determination from signals of normal turkey sera is misleading.

Fix OD reading: a fixed OD reading as cutoff point is not appropriate due to normal reading fluctuations between batch runs, between analysts, between days, between laboratories.

Data normalization of raw OD readings with a suitable positive control sample is necessary for appropriate interpretation of unknown samples. Comparison of results from different laboratories is difficult due to the lack of standardized reagents. Data normalization with a standard source of PC may be a helpful factor to narrow down the comparability of results from different laboratories.

For system suitability (batch run acceptance criteria), three controls are recommended in each batch run. Each control is analyzed in duplicate ( $N=2$; total four wells for two reportable values). Positive control serum is prepared in two levels at high positive control (HPC) and low positive control (LPC) and each analyzed in duplicates. Normal turkey serum is analyzed in duplicate as 
NC. Wells that contain all reagents except serum samples are nonspecific background (blank). The general acceptance criteria for these controls in each batch run are based on OD readings. At least two-thirds of controls should have readings in the following order: $\mathrm{HPC}>\mathrm{LPC}>\mathrm{NC}$.

For data normalization, the reading of LPC is suggested in the calculation of ELISA value or S/P ratio of each test serum.

With a HPC in the calculation of $S / P$ ratio in our laboratory, the optimum cutoff point is 0.18 for antibody-capture ELISA using IBV as the coating antigen, while the optimum cutoff point is 0.2 for ELISA using recombinant $\mathrm{TCoV} \mathrm{N}$ protein as the coating antigen.

10. Coating buffers of various salts may be applied. Results are comparable with phosphate and carbonate based buffers. There are many different kinds of plates with different performance purpose. MaxiSorp ${ }^{\circledR}$ plate gets consistent results for this ELISA method.

11. Coating overnight is minimum. Coating incubation over the weekend is routinely performed without noticeable impact to the assay. It is generally noted that incubation up to 5 days does not affect the ELISA results.

12. ELISA method with the recombinant $\mathrm{TCoV} \mathrm{N}$ protein as coating antigen has higher reactivity than that with IBV as coating antigen. The dilution factors for serum samples and conjugates are adjusted accordingly. The minimum required dilution of serum samples is 1:800 for the assay with $\mathrm{N}$ protein compared to $1: 40$ for the assay with the IBV. The conjugate dilution factor is 1:10,000 for the assay with $\mathrm{N}$ protein compared to $1: 1600$ for the assay with the IBV.

13. Prevalence, sensitivity, specificity, predictive values: The assay sensitivity and specificity of both ELISA methods relative to IFA are considered comparable. With assumptions of relative sensitivity at $90 \%$, relative specificity at $95 \%$, and disease prevalence at $55 \%$, positive predictive value (PPV) and negative predictive value (NPV) of these two ELISA methods are estimated below:

$$
\begin{array}{cc}
\mathrm{PPV}= & \text { Sensitivity } \times \text { prevalence } \\
\mathrm{NPV}= & =96 \% \\
\text { Sensitivity } \times \text { prevalence }+(1-\text { specificity }) \times(1-\text { prevalence }) & \\
\text { Specificity } \times(1-\text { prevalence }) & =89 \% \\
(1-\text { sensitivity }) \times \text { prevalence }+ \text { specificity } \times(1-\text { prevalence }) &
\end{array}
$$




\section{Acknowledgements}

The protocol “Antibody-capture enzyme-linked immunosorbent assay for detection of antibody to turkey coronavirus using infectious bronchitis virus or recombinant nucleocapsid protein as coating antigen" outlined in this chapter had been successfully carried out in the authors' studies on characterization, immunology, and diagnostic serology of turkey coronavirus infection in turkeys. Those studies were in part financially supported by USDA, North Carolina Poultry Federation, and/or Indiana Department of Agriculture and technically assisted by Drs. Tom Brien and David Hermes, Mr. Tom Hooper, and Ms. Donna Schrader in clinical and diagnostic investigation, virus isolation and propagation, and animal experimentation.

\section{References}

1. Nagaraja KV, Pomeroy BS (1997) Coronaviral enteritis of turkeys (blue comb disease). In: Calnek BW, Barnes HJ, Beard CW et al (eds) Diseases of poultry, 10th edn. Iowa State University Press, Ames, IA

2. Pomeroy BS, Larsen TC, Deshmukh RD, Patel LB (1975) Immunity to transmissible coronaviral enteritis of turkeys (Blue comb). Am J Vet Res 36:553-555

3. Loa CC, Lin TL, Wu CC, Bryan AT, Thacker HL, Hooper T, Schrader D (2000) Detection of antibody to turkey coronavirus by antibodycapture enzyme-linked immunosorbent assay utilizing infectious bronchitis virus antigen. Avian Dis 44:498-506

4. Loa CC, Lin TL, Wu CC, Bryan TA, Hooper T, Schrader D (2004) Expression and purifica- tion of turkey coronavirus nucleocapsid protein in Escherichia coli. J Virol Methods 116: 161-167

5. Abdelwahab M, Loa CC, Wu CC, Lin TL (2015) Recombinant nucleocapsid proteinbased enzyme-linked immunosorbent assay for detection of antibody to turkey coronavirus. J Virol Methods 217:36-41

6. Garwes DJ, Bountiff L, Millson GC, Elleman CJ (1984) Defective replication of porcine transmissible gastroenteritis virus in a continuous cell line. Adv Exp Med Biol 173:79-93

7. Ignjatovic J, McWaters GP (1993) Monoclonal antibodies to three structural proteins of avian infectious bronchitis virus: characterization of epitopes and antigenic differentiation of Australian strains. J Gen Virol 72:2915-2922 